\title{
Review of Management Strategies to Achieve Vision 2020 in India with Emphasis on Cataract Related Blindness
}

\section{Mukherjee B* \\ Consultant Ophthalmologist \& Medical Superintendent, India}

*Corresponding author: Bhaskar Mukherjee, Consultant Ophthalmologist \& Medical Superintendent, Dr. Nihar Munsi Eye Foundation, 1/3 Dover Place, 7 C, Abinash Banerjee Lane, Kolkata-700010, West Bengal, India, Tel: 91-33-98300 73412; Email: drbhaskarmukherjee@hotmail.com

\section{Review Article \\ Volume 2 Issue 6}

Received Date: November 07, 2019

Published Date: November 25, 2019

DOI: $10.23880 /$ jqhe- 16000145

\section{Abstract}

A review article to find out possible managerial solutions in order to achieve elimination of cataract related blindness in India by 2020. About 285 million people are visually impaired globally of which 39 million are blind. 80 percent of the total or 228 million people have avoidable blindness suffering from cataract, trachoma, onchocerciasis, refractive error, childhood blindness, low vision, glaucoma and diabetic retinopathy. Vision 2020 was initiated in February 1999 by WHO and IAPB to eliminate avoidable blindness. Prevalence of blindness in India is 1 percent. 7.2 million Indians are blind due to cataract and 6.5 million cataract cases are added every year. Presently India is performing 6 million cataract surgeries annually. Will India be able to achieve Vision 2020, since 50 plus age group population is increasing? These are the possible managerial solutions:

$>$ Proper execution of $12^{\text {th }}$ five year plan of National Program for Control of Blindness at government level.

$>$ Wider coverage of the below poverty line population under Rastriya Swastha Bima Yojona.

$>$ Training and implementation of low cost high volume cataract surgery like Manual Small Incision Cataract Surgery.

$>$ Involvement of more corporates to perform Corporate Social Responsibility through eye institutions in order to remove cataract related blindness.

Keywords: Cataract Related Blindness-Vision 2020-Indian; Scenario-Managerial Strategies-NPCB-RSBY-MSICS-CSR

Abbreviations: WHO: World Health Organization; IAPB: International Agency for the Prevention of Blindness; RSBY: Rashtriya Swasthya Bima Yojana; CSR: Corporate Social Responsibility; NPCB: National Programme for Control of Blindness; PE: Phacoemulsification; MISCS: Manual Small Incision Cataract Surgery; ECCE-IOL: Extra Capsular Cataract Surgery with Intraocular Lens Implantation; CBCP:
Cataract Blindness Control Program; SNC: Sadguru Netra Chikitsalaya; MESU: Mobile Eye Surgical Unit; IOL: Intraocular Lens.

\section{JEL Classification}

I 1, I 18 


\section{Journal of Quality in Health Care \& Economics}

\section{Introduction}

\section{Blindness}

According to WHO, blindness is defined as visual acquity in better eye is less than $3 / 60$ or inability to count fingers in daylight at a distance of 3 meters. Preventable blindness is the blindness which can be prevented by attacking the causative factors like corneal blindness (vitamin-A deficiency, trachoma, infectious keratitis etc). Industrial blindness (by improving occupational safety conditions), ROP, Diabetic retinopathy, etc. Curable blindness is almost synonymous with cataract blindness. Others are glaucoma, inflammation of ocular tissues etc. Avoidable blindness includes both preventable and curable blindness. 85 percent of the blindness is estimated to be avoidable [1].

\section{Vision 2020}

In order to achieve a world in which no one is needlessly blind and where those with unavoidable vision loss can achieve their full potential, Vision 2020 was initiated. Launched in February 1999, Vision 2020 is the global initiative for the elimination of avoidable blindness, a joint programme of the World Health Organization (WHO) and the International Agency for the Prevention of Blindness (IAPB) with an international membership of NGO's, professional associates, eye care institutions and corporations. Five conditions have been identified as immediate priorities within the framework of VISION2020 Programme. They are-Cataract, Trachoma, Onchocerciasis, Childhood blindness, Refractive error and low vision. In India, as there is no Onchocerciasis and Trachoma is declining, two more diseases are included recently in VISION 2020 India programme. These are Diabetic retinopathy and Glaucoma. They need special attention by all levels of eye health care personnel.

\section{Objectives of VISION 2020}

- Increase awareness, within key audiences, of the causes of blindness and the solutions to the problem.

- Advocate for secure the necessary resources to implement the WHO Global Action Plan 2014-19.

- Facilitate the planning, development and implementation of national VISION 2020/Eye Health programmes in all countries.

National programmes have three main elements:

- Cost effective disease control

- Human resource development

- Infrastructure and technology
VISION 2020 is built on a foundation of community participation. Overarching issues, such as equality, quality of services, visual outcomes and access the components of Universal Eye Health are addressed as a part of national programs [2].

\section{Cataract Related Blindness: Present Indian Scenario and the Problem}

In India, $80 \%$ of Blindness is due to cataract. Various modifiable risk factors associated with cataract include UV exposure, diabetes, hypertension, body mass index, drug usage, smoking and socio economic factors, but advancing age is the single most important risk factor for cataract. Nirmalan, et al. [3] studied the prevalence of cataract in a rural population ( $>40$ years) of Southern India as $47.5 \%$; prevalence is more in women than men. Vashist, et al. reported prevalences of 58\% in North India and 53\% in South India in older age group (> 60 years). Overall, increasing age, lower socio economic status and Diabetes are found to be risk factors for cataract related blindness in India [4].

\section{Eye Health Global Overview: Progress and Challenges}

About 285 million people are visually impaired about 39 million of who is blind. $80 \%$ of the total or around 228 million people are avoidably impaired. Women are more vulnerable, in some contexts they are less likely to access services, and they are at great risk of some conditions such as trachoma. The rapidly increasing prevalence of diabetes, projected to rise to 552 million in 2030, will mean greater incidence of diabetic retinopathy and additional strains on health systems and eye health personal. Reducing avoidable blindness and rehabilitating those who are irreversibly visually impaired have enormous implications for the individual, their families and their communities. Preventing blindness increases access to education, employment, and enables greater participation in civil, political and social life. The economic arguments for eye health by research data shows for every dollar spent on improving eye health services, there is more than two fold return on investment, and in developing countries, the investment generates four fold returns [5].

The main elements a government needs to put in place to achieve Universal Eye Health are:

$>$ Comprehensive eye care services-offering a breadth of services covering the range of causes of vision impairment, from promotion, prevention to rehabilitation and care. 


\section{Journal of Quality in Health Care \& Economics}

$>$ Eye health integrated into health systems, attending to the six building blocks of a health system according to WHO: governance, human resources, medicines and technologies, and information.

$>$ Access for everyone, including the poor, minorities, the disabled including vision impaired and people in rural areas. This requires adequate health outreach and promotion including in appropriate technologies and formats, and ensuring mainstream and targeted programs address barriers.

$>$ Point-of-care payment should not prevent access: It should be free for the poorest.

\section{India: Towards Universal Eye Health}

Most eye care programs in India have been structured around cataract, initially through surgical eye camps and then building the hospital base. India now has a good network of secondary eye hospitals in the voluntary and government sector. The primary eye care approach has become part of India's National Program for control of blindness. Funds have been allocated to establish 5000 primary eye-care centers during the $12^{\text {th }}$ five year plan. While there has been some progress in both government and voluntary sectors, more infrastructures is required. Enabling policies, minimum standards and technologies are also needed to expand eye-care services at the community level [6].

\section{Prevalence of Cataract in India}

Survey conducted by MoH \& FW during the year 200607 revealed that prevalence of blindness has come down from $1.4 \%$ to $1 \%$. Along with other cause of blindness; cataract still remains the major challenge, due to raised awareness, increased longevity of life and increasing population. Considering current population (121 crore) of India as per census 2011, 1\% blindness constitutes approximately 1 crore 21 lakhs. Out of this approximately $62 \%$ i.e., 7.2 million are blind due to cataract. As per NPCB incidence of cataract is 0.4 to $0.5 \%$ thus the number of new cases of cataract to be operated upon each year comes to 6.15 million. Approximately 7 million people are blind due to cataract at any point of time (prevalence) and 6.15 million cataract cases are added each year (Incidence).India is performing 6 million cataract surgeries every year [7].

Achieving major public health impact requires interventions which should reach a large share of those who need them and are effective and affordable. In many of the cases, the greatest challenge was to ensure access to a simple and cost-effective technology or treatment that could be delivered or administered by basic health workers. In the case of treating millions of cataract suffers in India, the task was to reach those in need and to ensure that the surgical treatment offered was of adequate quality to solve the problem, without needless complications. This represents a vast challenge, given major limitations in both the reach and quality of health care delivery in India, but one that the government, working with the key partners and deploying low-cost technologies, has been able to accomplish to as remarkable degree. The cataract program in India, in its several phases, demonstrates some of the key features of "scaling up": introducing better and affordable technologies when they become available, building demand for a service that was previously unavailable, and getting to low unit costs by serving large numbers of patient efficiently. Initially, the goal of a broad coverage of services to treat blindness and severe vision loss was achieved by public education to convince people that treatment was possible, and by the use of "eye camps" to bring screening and treatment services to remote and impoverished areas that had not previously been well served by either government or private providers. Services then needed to be reoriented and upgraded, focusing on quality as well as quantity. Achieving good outcomes from treatment required the systematic introduction of improved techniques, training and retraining, attention to monitoring and partnership between government and a broad range of funding and service-provision organizations to achieve high-volume, low-cost surgery.

\section{Current Status of Cataract Blindness in India and the Apprehension}

But is it enough to solve the problem? What is the ground reality of cataract related blindness in this country and whether India will be able to achieve VISION 2020? A recent study shows-Using age-specific data for those aged $50+$ years it was observed that prevalence of blindness at different age cohorts (above 50 years) has reduced over three decades with a peak in 1989. Projections show that among those aged 50+ years, the quantum of cataract surgery would double (3.38 million in 2001 to 7.63 million in 2020) and cataract surgical rate would increase from 24025/million 50+ in 2001 to $27817 /$ million $50+$ in 2020 .Though the prevalence of cataract blindness would decrease, the absolute number of cataract cases would increase from 7.75 million in 2001 to 8.25 million in 2020 due to a substantial increase in the population above 50 years in India over this period. Considering existing prevalence and projected incidence of cataract blindness over the period 2001-2020, visual 


\section{Journal of Quality in Health Care \& Economics}

outcomes after cataract surgery and sight restoration rate, elimination of cataract blindness may not be achieved in India [8].

\section{The Possible Solution}

Therefore, in order to achieve VISION 2020 in India, the following management strategies may be implemented as they have successfully reduced prevalence of Cataract related blindness presently to $1 \%$, as per NPCB statistics.

$>$ Execution of $12^{\text {th }}$ Five year Plan (NPCB) at the government level.

$>$ Wider coverage of the national population under Rashtriya Swasthya Bima Yojana (RSBY) scheme for cataract surgery.

$>$ Training and implementation of high volume low cost cataract surgery (MSICS): The Arvind model and other projects.

> Involvement for more corporate sectors to execute corporate social responsibility (CSR) for cataract surgery.

\section{National Programme for Control of Blindness (NPCB): $12^{\text {th }}$ Five Year Plan}

NPCB was launched in the year 1976 as a $100 \%$ centrally sponsored scheme with the goal of reducing the prevalence of blindness to $0.3 \%$ by 2020 . Rapid survey on avoidable blindness conducted under NPCB during 200607 showed reduction in the prevalence rate of blindness from 1.1 percent (2001-02) to 1 percent (2006-07). With a view to achieve the above said objective, the government has decided to continue this scheme during the $12^{\text {th }}$ plan with increased assistance for various components under the scheme.

\section{Objectives}

$>$ To reduce the backlog of blindness through identification and treatment of blind at primary, secondary and tertiary levels based on assessment of overall burden of visual impairment in the country.

$>$ Develop and strengthen the strategy of NPCB for "Eye Health" and prevention of visual impairment, through provision of comprehensive eye care services and quality service delivery.

> Strengthening and up gradation of RIOs to become center of excellence in various sub-specialties of ophthalmology.

> Strengthening the existing and developing additional human resources and infrastructure facilities for providing high quality comprehensive Eye Care in all districts of the country.

$>$ To enhance community awareness on eye care and lay stress on preventive measures.
Increase and expand research for prevention of blindness and visual impairment

$>$ To secure participation of Voluntary Organization/Private Practitioners in eye care.

\section{Strategies}

Decentralized implementation of the scheme through District Health Societies (NPCB).

> Reduction in the backlog of blind persons by active screening of population above 50 years, organizing screening eye camps and transporting operable cases to eye care facilities.

$>$ Development of eye care services and improvement in quality of eye care by training of personnel, supply of high-tech ophthalmic equipment, strengthening follow up services and regular monitoring of services.

> Screening of school age group (Primary \& Secondary) children for identification and treatment of Refractive errors, with special attention in under-served areas.

$>$ Public awareness about prevention and timely treatment of eye ailments.

$>$ Special focus on illiterate women in rural areas. For this purpose, there should be convergence with various ongoing schemes for development of women and children.

$>$ To make eye care comprehensive, besides cataract surgery, provision of assistance for other eye disease like Diabetic Retinopathy, Glaucoma Management, Laser Techniques, Corneal transplantation, Vitreoretinal Surgery, treatment of childhood blindness etc.

$>$ Construction of dedicated eye wards and eye OT's in district hospitals in NE states and few other states as per need.

$>$ Development of mobile ophthalmic units in the district level for patient screening and transportation of patients

$>$ Continuing emphasis on primary healthcare (eye care) by establishing vision centers in all PHC's.

$>$ Participation of community and Panchayat Raj institutions in organizing services in rural areas

$>$ Involvement of private practitioners in the program.

\section{Target for the $12^{\text {th }}$ Plan}

During the $12^{\text {th }}$ Plan, the scheme would consolidate gains in controlling cataract blindness and also initiate activities to prevent and control blindness due to other causes. This would be done by further increasing cataract surgery rate, increasing coverage, providing assistance for treatment of other eye diseases, strengthening of existing eye care infrastructure and developing new eye care infrastructure and human resources, involvement of community including panchayats and voluntary 


\section{Journal of Quality in Health Care \& Economics}

organizations etc. The scheme would be uniformly implemented throughout the country. Funds for implementation of the scheme would be utilized on the on the following activities:

$>$ Performing 3.3 crore cataract operations with above $95 \%$ being IOL implementation

$>$ Assistance to NGOs for management of other eye diseases (other than cataract) like Diabetic Retinopathy, Glaucoma Management, Laser techniques, corneal transplantation, Vitreoretinal, Treatment of childhood blindness etc.

$>$ Screening of school age group for detection of refractive errors and providing 44 lakh free spectacles to poor school age group children.

$>$ Spectacles for near work (Presbyopia) to 10 lakh old persons.

$>$ Setting up 5000 vision centers at Rs 1 lakh with basic screening equipment catering 50000 populations per center.

$>$ Enhancing capacities for eye care services in public sector by providing assistance to hospitals at various levels.

$>$ Training of other medical personal including nurses in ophthalmic techniques, ophthalmic assistants etc.

$>$ Collection of 2.50 lakh donated eyes(after death) for transplantation in persons with corneal blindness

$>$ Providing non-recurring assistance to 20 voluntary organizations at Rs 40 lakh for setting up/expanding eye care services for semi urban/rural population.

$>$ Strengthening of existing 20 lakh eye banks at Rs 25 lakh and 100 eye donation centres at Rs1 lakh to facilitate collection and processing of donated eyes.

$>$ Construction of 25 dedicated eye wards and eye 0Ts renamed as dedicated eye unit in district hospitals in states as per need.

$>$ Utilizing ophthalmic manpower such as-eye surgeons, ophthalmic assistants, eye donation counsellors, outside government sector on contractual basis.

$>$ Intensive use of IEC to promote awareness among masses about eye care.

$>$ Setting up of 400 multipurpose district mobile ophthalmic units as per the need.

$>$ Involvement of private practitioners in the program.

> Maintenance of ophthalmic equipment supplied to regional institutes of ophthalmology, medical colleges, district/sub-district hospitals, PHC/Vision centers.

$>$ Strengthening of training activities for eye care personnel to get the knowledge of modern eye care techniques and ultimately its utilization for the benefits of the public.

$>$ Regular monitoring and evaluation through management information system to ensure more transparency in funds utilization and access of real time data as well as release of funds on the basis of data entry in MIS (NPCB) by NGOs/private sector [7].

\section{Rashtriya Swasthya Bima Yojana}

Rastriya Swasthya Bima Yojana (RSBY) literally means National Health Insurance Program. It is a governmentrun health insurance scheme for the Indian poor. It provides for cashless insurance for hospitalization in public as well as private hospitals. The scheme started enrolling on April, 2008 and has been implemented in 25 states of India. A total of 36 million families have been enrolled as of February 2014. In the starting RSBY was a project under the Ministry of Labor and Employment. Now it is transferred to Ministry of Health and family welfare from April, 2015. Every 'below poverty line' (BPL) family holding a yellow ration card pays Rs30/registration fee to get a biometric-enabled smart card containing their fingerprints and photographs. This enables them to receive inpatient medical care of up to Rs $30000 /-$ per family per year in any of the empanelled hospitals. Pre-existing illnesses are covered from day one, for head of household, spouse and up to three dependent children or parents. In the Union Budget for 2012-13, the government made a total allocation of Rs1096.7 crore towards RSBY. Although meant to cover the entire BPL population, (about 37.2 percent of the total Indian population according to the Tendulkar committee estimates) it had enrolled only around 10 percent of the Indian population by March31, 2011. Also, it is expected to cost the exchequer at least Rs3350/-crore a year to cover the entire BPL population. The scheme has won plaudits from the World Bank, the UN and the ILO as one of the world's best health insurance schemes. Germany has shown interest in adopting the smart card model for revamping its own social security system, the oldest in the world, by replacing its current, expensive system of voucher based benefits for 2.5 million children. The IndoGerman Social Security program, created as part of a cooperation pact between the two countries is guiding this collaboration. One of the big changes that this scheme entails is bringing investments to unnerved areas. Most private investments in healthcare in India have been focused on tertiary or specialized care in urban areas. However, with RSBY coming in, the scenario is changing. New age companies like Global Healthcare Systems, a company based out of Kolkata and funded by Tier 1 Capital Funds like Sequoia Capital and Elevar Equity are setting up State of Art Hospitals in Semi Urban-rural settings. This trend can create the infrastructure that India's healthcare system desperately needs [9]. 


\section{Journal of Quality in Health Care \& Economics}

Training and Implementation of High Volume and Low Cost Cataract Surgery (MICS): the Arvind Model and Other Projects

In order to set priorities to reduce blindness, it is important to identify the targets for the priorities. 'Developing countries' is the most commonly talked about target for control of blindness control programs. However, it is apparent that even within a country, significant variation in the magnitude of blindness exist among the various socioeconomic status groups. It would then seem prudent to set priorities based on these observed inequalities for the blindness scenario to be improved. Many studies around the world have identified the groups likely to have higher risk of blindness-those with lower monthly income, with no education, females, and ethnic minorities. In order to have effective strategies for reduction of blindness, it is imperative that the blindness control programs actively target these groups in the population. Global data on blindness suggest that cataract, refractive error, and trachoma are the most important causes of blindness in developing countries whereas age related macular degeneration is the most common cause in established market economies. This suggests that the prevalence of blindness due to avoidable causes is higher in countries with poor socioeconomic status [10].

Economic and social factors have been reported as a barrier preventing patients from undergoing cataract surgery in developing countries. The various barriers to cataract surgery include poverty, lack of transportation infrastructure, gender, low awareness levels, accessibility, and cost. Lack of social support, such as finding an escort or obtaining permission from other family members, especially husbands for women patients, has also been reported as a barrier to obtain surgery. Many high-risk, elderly cataract patients in the developing countries including India might not have their own money and may be dependent on their family for support. Literature also reports that success of strategies for reducing cataract backlog are related not only to surgical considerations but also to equally important issues related to the levels of education, economic wealth, and occupation for cataract patients and their guardians. Research in India has shown that a significant proportion (around 40 percent) of people with eye problems report reasons such as 'God's will', 'Too Old', 'No point' and other 'Miscellaneous Reasons' for nonuse of eye care services . Perhaps, this is indicating that a person understands of cataract and its treatment is an important explanatory factor for the nonuse of eye care services. Most of the studies investigating barriers to the use of eye care services have taken the patient's point of view, but not the household's view. Literature states that 'some of the factors determining acceptance of surgery involve complex family and social processes unfolding over several months or sometimes years', inspite of the fact that cataract surgery benefits not only patients but also family members.

A study shows although females comprised 60.5 percent of all cataract operated in a particular population in India, the surgical coverage for females was still 18.7 percent lower than males. Difference in surgical coverage between sexes increased with age-males aged 50-59 years received 16.6 percent more surgery than females, and those aged 70 years received 25.6 percent more surgery than females. Eye care programs need to be made aware that achieving sex equality in cataract surgery may mean more than operating on equal number of male and female patients. Results indicate that sex inequalities may persist even in settings that have a high surgical coverage and that three cataract blind females have to be operated on for every two cataract blind males operated to achieve sex equality [3].

In another study, having more than three babies may substantially increase the risk of sight impairing cataract in mothers of childbearing age in central India. The findings open new research challenges to identify cataract risk factors to which mothers may be exposed during pregnancy and childbirth, particularly under poor socioeconomic conditions [11].

\section{Procedures for Cataract Surgery:}

$>$ Phacoemulsification(PE)

$>$ Manual small incision cataract surgery(MSICS)

$>$ Extra capsular cataract surgery with intraocular lens implantation (ECCE-IOL)

$>$ Femto second laser cataract surgery

In order that people can come for surgery in large number, demand for cataract surgery must be created in the community. People must be aware. They must know that the condition they have is cataract that surgery gives good results, and where to go for surgery. People must have access. There must be services available within reach; family members must be willing to support or allow the person to undergo cataract surgery, and any other barriers to attending for surgery must be successfully addressed. People must be able to afford cataract surgery, including any associated cost. Also 


\section{Journal of Quality in Health Care \& Economics}

patients and their family must be confident in the quality and safety of surgery.

\section{Economic Cost of Cataract Surgery Procedures}

A study showed average provider's direct cost was highest for PE procedures (25.55 US dollars) compared to MSICS (17.03 US dollars) and ECCE-IOL (16.25 US dollars). The difference can be attributed to the cost of equipment and materials. Average direct and indirect patient costs were highest for ECCE-IOL (19.85 US dollars), while the costs for PHACO and MSICS were identical (12.37 US dollars). ECCE-IOL had the highest total costs and MSICS had the lowest total costs from societal perspective. Therefore, Government and NGO hospitals providing cataract surgeries should invest in regular cost analyses, reviews of the literature on effectiveness, and formal cost-effectiveness analyses in order to plan economically effective interventions [12].

In health programs, where there is chronic scarcity of funds, as evidenced by a 20 percent reduction in health from annual national budget (India Today December, 2014), interventions which are cheaper and yet provide equally good outcomes should be adopted and actively propagated. Study shows that MSICS is comparably as effective as PE in terms of visual rehabilitation and increasing the quality of life in cataract patients. However, MSICS is significantly less expensive and does not require the capital expenditure and maintenance of Phaco machine which requires a dependable source of energy, which is usually a limiting factor in developing countries. Training in PE also has a steeper learning curve. The foldable IOL's used in PE are also far more expensive than the rigid polymethyl methacrylate IOL's used in MSICS. Treating cataract in the developing world is a formidable challenge with significant barriers like cost, lack of awareness and shortage of trained personnel. MSICS with its shorter surgical time and its requirement for less expensive and less technology dependent equipment can help in overcoming this challenge. Health care expenditures are continuously rising throughout the world. Regular cost-effectiveness studies should be carried out in various fields to look for the best intervention amongst the alternatives. This will ensure proper channelization of resources for a sustainable growth in the medical field [13].

Until recently, MSICS was considered as a low-tech, unproven poor cousin to the gold standard phacoemulsification. Several recent articles have compared MSICS to PE and demonstrated almost equivalent outcomes. Moreover, how much ever we may espouse providing the gold standard for the entire cataract population, in reality even if that were desirable, "phacoemulsification for all" (cataracts) in India is neither practical nor feasible. The advantages of MSICS as lowcost "equally effective" technique makes it an alternative, especially in an unequally developed country like ours. Therefore, in order to make sight affordable and to remove cataract related blindness from India, high volume low cost cataract surgery is the answer. This could be achieved through the Arvind Model and various other community assisted models.

\section{Aravind Eye Hospital Model}

The Aravind Eye Care System, an NGO with a 30-year history of providing very low-cost vision care, has been a leading partner to the government of India in its blindness program and a leading example of social entrepreneurship in the health sector. Among the NGOs providing cataract treatment in India, Aravind is by far the largest, conducting more than 1000 screening camps and performing close to 1 million cataract surgeries each year. Within the context of Cataract Blindness Control Program (CBCP), Aravind's role was particularly significant in Tamilnadu, where some 95 percent of the surgeries were performed under the organization's auspices. Aravind had its start in 1976 when its founder, Dr. Govindappa Venkataswamy, after mandatory retirement from government service at age 58, opened a 12-bed hospital in the South Indian city of Madurai. Starting with a little money but a strong sense of mission toward saving the vision of those in need and inspired serendipitously, by the large scale success of the McDonald's fast food marketing strategy, over time Dr. Venkataswamy established a network of specialty eye hospitals throughout India that uses a sustainable business model to provide high-quality patient care. He devoted himself to this effort until his death in 2006, his family continues his work. Three key elements define the Aravind business model:

$>$ Economies of scale-With excellent management and high patient volume, Aravind keeps productivity high, with surgeons performing 25-40 procedures daily; unit costs are maintained at the very low level of about 10 USD per cataract operation.

$>$ Cross-subsidies-Aravind provides free or very lowpriced care to two-thirds of its patients with the revenue derived from the one-third of patients who are able to pay moderate prices. The only difference in the treatment of those who do and don't pay is the amenities, such as the air conditioning in the recovery room. 


\section{Journal of Quality in Health Care \& Economics}

Vertical integration-Recognizing that the imported intraocular lenses constituted a major component of the total surgical costs, Aravind obtained a transfer of technology through the US-based Seva Foundation, and additional support from the Combat Blindness Foundation, to permit it to manufacture these lenses at a fraction of the cost. The manufacturing activity scaled up quickly, from 35000 in 1992-93 to nearly 600000 lenses in 2000. Now, at the Aurolab subsidiary established for this purpose, a workforce of about 200 young women from the rural backgrounds produces lenses to a global standard of quality that are used at Aravind, as well as at facilities throughout India. The affordably priced intraocular lenses are exported to 85 countries around the world, providing another source of revenue for Aravind. The system of eye hospitals also is considered one of the India's premier ophthalmic training institutions, providing a steady flow of wellprepared professionals and support staff. Aravind got financial and technical support from WHO, Seva Foundation. Lion's Club, Sight savers International, Christoffel Blinden Mission etc [14].

\section{The SNC Model}

Sadguru Netra Chikitsalaya (SNC), Sri Sadguru Seva Sangh Trust, Chitrakoot, is located in a remote and economically deprived region in Central India, It is one example of a hospital which has been able to create demand for cataract surgery even amongst hard-to-reach, and had also made surgery affordable. To overcome the barriers, the hospital management initiated an outreach program in the summer months. Free eye check-ups, free transportation and free diet and counseling services motivated people to accept the services and this led to a gradual increase in the volume of patients. To raise awareness of the services offered, SNC distributed educational materials, organized regular meetings with the influential members of the community and engaged the local community in key events at the hospital. To reduce fear, which affects people's willingness to accept surgery, SNC adopted the following approaches:

Using a model (dummy) lens during counseling to explain to patients about IOL implants.

$>$ using the local language or dialect to counsel the patients

$>$ explaining the facilities available in the hospital

Today, SNC is engaged in providing outreach services through ten outreach teams and 26 vision centers within a $250 \mathrm{~km}$ radius of the hospital [15].

\section{The SN Model}

Sankara Nethralaya was started by Dr. SS Badrinath, a young vitreo-retinal surgeon of international repute, to fill the wide gap between the need and availability of eye care in the country at a time when ophthalmic disorders were treated along with other ailments in a general hospital. It was started with the Nobel objective of providing world class eye care with a personal touch at nominal costs to paying patients and totally cost free to indigent patients without any disparity. SN treats 40 percent of its patients totally cost free, this includes the large number of patients who turn up at the Jaslok Ophthalmology Center, its community care center in Chennai and its centers throughout the country every day and patients screened at the large number of outdoor community screening camps, it is noteworthy that patients needing treatment at the outdoor eye screening camps are transported to the base hospital, provided food, shelter, treatment including surgery, medicines and dropped back at their village totally cost free. SN is the only eye care institution which performs cataract surgeries right at the door step of the patients; this is made possible through the Mobile Eye Surgical Unit (MESU), a medico-engineering marvel, an operation theatre on wheels developed jointly with the IIT-Madras. MESU performs surgery totally cost free to the most socially and economically backward people with very low awareness levels living in the most remote, inaccessible regions of the country including hilly, tribal pockets not served by the most basic Medicare, people who would not be able to avail eye care if it is provided cost free in a base hospital due to many reasons [16].

\section{The CAFE Model}

Community assisted and financed eye care project was initiated in 16 villages of West Godavari district, in Andhra Pradesh, between October2001 and February 2006. The idea was to create a community fund for eye care on the basis of the participation of all members of a captive community, irrespective of any determinants. It was implemented through a field team that collected a payment of one rupee per person per month on a yearly basis for the entire family. An identity card, ensuring accountability, costing five rupees was issued for each person, with a photograph that was taken by field workers. This fund collected from the members of the community covered a complete eye examination at the secondary level eye care center, including cataract surgery with intraocular lens (IOL) implantation when needed and minor surgeries in the economy category(costing the equivalent of USD25). More than 70 


\section{Journal of Quality in Health Care \& Economics}

percent of the population of these villages registered, the approximate population included was 50000. Over a period of four years, 65 percent of the families utilized the hospital services, with 23637 outpatients and 1805 children examined and 1859 cataract surgeries with IOL performed [17].

\section{Corporate Social Responsibility}

Corporate social responsibility (CSR) has been an uprising issue for the last two decades. It has been developed from US and Europe simultaneously over series of irresponsible activities from large MNCs. Since the beginning of the new concept, global companies have revised their code of conducts and ethical regulations to be able to prove to their stake holders that they are a responsible business entity and that the profit given back to the shareholders are not from unethical practices. CSR involves multiple stakeholders, including the government, shareholders, employees, consumers, media, suppliers, NGOs, and the general public. CSR has been defined by many groups. Although they all bear similar meanings relating to taking responsibilities of the society as a business entity, its definition has been getting wider from a traditional point of view of philanthropy and volunteerism to do the business in a responsible way.

The Government of India has passed the amended law on "Companies Bill 2011" making it mandatory for-(1) Companies who have reported a net profit of 5 crores or more in the last 3 years to spend 2 percent of their profits on discharging their Corporate Social Responsibility( CSR). 2 Companies with a market capitalization of more than 500 crores to spend 2 percent of their annual net profits on discharging their CSR. The corporate who are fulfilling their CSR with Sankara Nethralaya are-Land T, IOC, ONGC, Bajaj group, TATA, Birla group, Reliance group, SBI, IDBI, UBI, Cognizant Technologies, Google Foundation, USA, Nathella Sampathu chetty charities, Amalgamations group, TVS group, HDFC, Stanchart Bank, CPCL,Wonderwork, USA [18].

Ajanta pharma limited performs their CSR by conducting large eye care camps in various villages where free cataract operations and eye checkups are provided to the underprivileged, through services of eye specialists and surgeons. All patients undergoing eye operations are also provided with adequate post-operative care. In FY 2013-14, they had performed 24000+ cataract surgeries successfully [19].
Canon India performs their CSR through three core areas like Eye care, Education and Environment. The CSR policy aligns with the corporate philosophy "KYOSEI" which means living and working together for the common good. Employs are encouraged to volunteer their time and skills and enjoy the experience of giving back to the communities in which they work. The company had adopted various villages. A vision center had been established in these adopted villages. The centers provide support over adopted villages and neighboring groups of villages. The local panchayat allotted the space for the center, which remained open for four days in a week out of which two days were used for awareness campaigns around the village. The villages were provided with medicines and spectacles. Also, the surgeries were conducted at the base hospital $[20,21]$.

India is the home to $1 / 3^{\text {rd }}$ of world's blind population, the loss incurred by the nation on account of the nonproductive nature of such a huge population is very high, additionally the government spends a large amount on their upkeep and rehabilitation, hence it becomes the Corporate Social Responsibility of every responsible corporate citizen to support all eye care institutions earnest attempt towards eradicating blindness.

\section{Conclusion}

Charitable organizations can provide free transport for surgery and also motivate patients who have already undergone surgery to encourage their own relatives and community members who have cataract to get the surgery done. Charitable organizations can also motivate the potential treatment beneficiaries via health education and counseling to undergo surgery. Promoting the benefits of cataract treatment for older adults in household and in the community can also help in increasing the use of the surgery. Providing cost-effective suture less surgeries like manual small incision cataract surgery (MSICS) can help reduce the postoperative procedures and follow-up treatment. Facilitating a quick return to day-to-day responsibilities can help increase the use of surgery.

Most literature concentrates on the prevalence of cataract blindness in projecting future trends. However it is also important to consider the newly blinded individuals (incident cases of cataract blindness) as they would also need to be treated. The backlog of cataract blindness can be tackled effectively only if the incident cases are also accounted for. Unfortunately, estimates of incidence of cataract blindness are difficult to obtain 


\section{Journal of Quality in Health Care \& Economics}

because of long duration of the disease and the uncertainty of the pace of progression to blindness in cataract. Studies in South Africa and India have documented that the incidence ranges between 23-30 percent of prevalence [15].

According to the National Program for control of Blindness (NPCB), the following Indian states are under performing or have not achieved target cataract surgery as fixed by NPCB in the year 2016-2017. They are Jammu \& Kashmir, Jharkhand, Bihar, North Eastern States, Odisha, Chattisgarh, Karnataka \& West Bengal [7]. Lastly, as per report in Economic Times dated 30.8.'19, the National health authority has decided to remove cataract surgery from the ambit of AYUSHMAN BHARAT, the present India Governments health Insurance scheme for the poorest of the poor. This will definitely lead to the increase of cataract backlog population in India. Assuming that the incidence of newly blinded cataract is 20 percent, it appears that the present number of cataract surgeries need to be scaled up significantly if the elimination of avoidable cataract blindness is to be a reality by 2020 , thereby achieving the target of VISION 2020.

\section{References}

1. Basak S (2007) Essentials of Ophthalmology. $4^{\text {th }}$ (Edn.), Current Books International, Kolkata pp: 459.

2. (2015) Global Action Plan-South East Asia.

3. Nirmalan PK, Padmavathi A, Thulasiraj RD (2003) Sex inequalities in cataract blindness burden and surgical services in south India. Br J Ophthalmol 87(7): 490.

4. Singh S, Pardhan S, Kulothungan V, Swaminathan G, Ravichandran JS, et al. (2019) The prevalence and risk factors for cataract in rural and Urban India. Indian J Ophthalmol 67(4): 477-483.

5. http://www.iapb.org/advocacy/who_action_plan/UE $\mathrm{H}$-accessed

6. Global Action Plan 2014-2019. The International Agency for the Prevention of Blindness.

7. http://www.npcb.nic.in-accessed

8. Murthy GVS, Gupta SK, John N, Vashist P (2008) Current status of cataract blindness and Vision 2020: The right to sight initiative in India. Indian J Ophthalmol 56(6): 490-494.
9. www.rsby.gov.in-accessed on $01 / 11 / 2015$

10. Dandona R, Dandona L (2001) Socioeconomic status and blindness. British Journal of Ophthalmology 85(12): 1486.

11. Minassian DC, Mehra V, Reidy A (2002) Childbearing and risk of cataract in young women: an epidemiological study in central India. $\mathrm{Br} \mathrm{J}$ Ophthalmol 5(5): 435.

12. Muralikrishnan R, Venkatesh R, Prajna NV, Frick KD (2004) Economic cost of cataract surgery procedures in an established eye care centre in Southern India. Ophthalmic Epidemiol 11(5): 369-380.

13. Khan A, Amitabha KA, Rizvi SAR, Siddique Z, Kumari $\mathrm{N}$, et al. (2015) Cost-effectiveness analysis should continually assess competing health care options especially in high volume environments like cataract surgery. Indian J Ophthalmol 63(6): 496-500.

14. (2015) Aravind Eye Hospital, Madurai.

15. Murthy GVS, Jain BK, Shamanna BR, Subramanyam D (2014) Improving cataract services in the Indian context. Community Eye Health 27(85): 4-5.

16. http://www.sankaranethralaya.org/corporate_social _responsibility.htm-accessed on 12.11.2015

17. Pyda G, Shamanna BR, Murthy R, Khanna RC (2011) Financing eye care in India-Community- assisted and financed eye care project (CAFE). Indian J Ophthalmol 59(4): 331.

18. http://www.sankaranethralaya.org/corporate_social _responsibilty.html-accessed on 14.11.2015

19. http://www.ajantapharma.com/csr.html-accessed on16.11.2015

20. http://www.canon.co.in/personal/web/company/ab out/csr-accessed on 20.11.2015.

21. Muralikrishnan R, Venkatesh R, Prajna NV, Frick KD (2015) Economic and social factors that influence households not willing to undergo cataract surgery. Indian J Ophthalmol 63(7): 549-599.

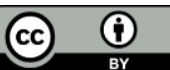

